\title{
Moving the Music: Dance, Action and Embodied Identity
}

\section{Sarie Mairs Slee}

Everybody dance now... Music makes me move my body, makes me move my soul... get into the groove... Everybody, rock your body... I've got the moves like Jagger... ${ }^{1}$

Once a child of the MTV generation and now a dance artist/academic, the rhythms and lyrics of popular music seem to me a call to action to get up and get moving. And while the visual and aural norms of music videos have evolved over recent decades, dance and designed physical movement remain a regular - if not primary- element of many twenty-first century music videos. Discourses on music videos widely examine the use of image within the video, along with visual animation and music consumption (Goodwin 2993, Whiteley 1997, Frith et al 1998). But dance is something that is not only seen but done, that is not only visual but kinaesthetic. Movement, dance and embodied action serve as constituent elements within the music videos which can move the listener/spectator from passive consumption through the ears and eyes into active participation through the body. The integration of dance within music videos seems intuitive: across histories, aesthetics and traditions, much of popular music has sought to evoke a physical response: from moshing to the Macarena, tribal trance to twerking, the aerial aerobics of swing dance to a Saturday night boogie around your handbag. Yet the design and integration of embodied action into the music video plays a deeper role in connecting the artist featured with his/her audience. This chapter seeks to examine the role of dance and the dancer's embodied identity within the music video. It draws from theories regarding embodiment, identity, and dance from across cultural studies, performance studies and the social sciences. In total, it aims to explore the use of dance and embodied action in the constructed identity of the singer, the embodied experience of the song, and the methods in which video-makers support the spectator's potential to transition from passive to active.

Despite the long-standing place for dance in music videos, it has received little analytic attention outside writings specifically on dance. In an early essay on dance in music videos, Angela McRobbie (1984) highlights gaps in the analysis of dance: "Of all the areas of popular culture, it remains the least theorised, the least subject to the scrutiny of the social critic" (130-131). Goodwin approaches the subject stating that "dance on music television and in music video has similarly been neglected..." and suggests an initial way of analyzing dance in videos is "through its attempt to visualize music." (1993: 68). He goes onto observe that:

\footnotetext{
${ }^{1}$ The lyrics referenced come from (in order of citation): 'Everybody Dance Now' by C+C Music Factory (1990), 'Dr. Beat' by the Miami Sound Machine (1984), 'Into the Groove' by Madonna (1984), 'Everybody' by The Backstreet Boys (1996), and 'Moves Like Jagger' by Maroon 5 (2010).
} 
various forms of pro-filmic movement- encompassing musicians, nonmusicians, professional dancers, and audience members, and ranging from full-fledged dance routines to all matters concerning gesture and the visual rhetoric of the body- may connect with synaesthesia through their efforts to visualise the music itself. Hebdige for instance, has written briefly on the links between the pace of punk rock music and style of pogo dancing that went with it" (Goodwin 1993: 69).

But, despite Goodwin's sound efforts to include dance in his analysis, the example given provides a better example of dance's work to embody music, rather than to simply visualise it. One must remember a key fact: when dancing, we cannot see ourselves dance. If it is accepted that dance in social settings is primarily participatory and only occasionally or secondarily presentational, then it is truly what is done, what is felt and what is experienced that drives the embodied reaction to music.

This understanding of dance as a participatory action changes its role as an element within the video. In modern popular music, the musicians are the main people active in making music; even if the actions of 'singing along' in the car or in a stadium concert are acceptable, it is understood that this an act of joining what is pivotally the musicians' role. But the same is not true for dance; from a gentle toe-tap to a full-bodied flail or flourish of torso and limbs, dance is a normalized reaction to and participation in popular music. It is something people do, rather than just see. Therefore, as a performative element of the music video, dance and movement hold potential for a different type of relationship with the viewer. It provides something that seems to flow from the music as 'authentic' physical response to the music - as performed by or alongside the musician - and holds possibility of being embodied in present or future responses to the music. Dance therefore becomes a kinaesthetic, action-based instrument that helps formulate the embodied identity of the song, and through the song, the artist: an identity that can be observed, experienced, consumed, extended, or transferred.

\section{Key Concepts in Dance and Embodied Action in the Music Video}

While rarely the focus in analysis, dance is regularly referenced in literature examining the music video. Dodds (2009) notes, "It is hardly surprising that the dancing body is a ubiquitous presence in pop music video. In both social and performance arenas, popular dance and music are inextricably linked" (247). The 'visual' is regarded as the key additional feature of the music video that separates it from the song the original - or at least separate - artefact: “... a pop video is essentially a specific visual representation of the musical content" (Whiteley 1997: 260). Much of the theory supporting 
this literature arises from popular music studies, which takes the 'music' as the primary subject frame, or film studies, which prioritizes the 'image', and creates the binary frame for analysis via the eyes and ears. By incorporating the 'body' to create a triadic frame, one recognizes both the fuller sensory complexity involved in the experience of music and recognizes the symbiotic relationship triggered between dance and music videos as described by Dodds:

Popular dance styles, both from vernacular and other screen traditions, serve as a visual illustration of the music; the music and the visuals, meanwhile, inform and influence the dance practices of the spectators who seek to embody the images that they see on screen" (2009: 248).

The incorporation of the body in the analysis of music videos also expands the consideration of the visual to both include image (noun) and action (verb). Goodwin also cautions the overreliance on film studies to read 'the visual' in music videos, but in this case for the dangers of omitting the visual elements - static and active - inherent in the music and the making of it.

My point is that visual spectacles (dancing, gesture, the display of virtuosity, lighting, smoke bombs, dry ice, back projection, etc.) have always worked in tandem with the music itself. Performances on music television mirror many of these codes and conventions (established in more than thirty years of rock and pop concerts), yet academic theorists frequently relate this iconography to filmic, postmodernist and... psycho-analytic categories without taking account of its more prosaic intention - that of evoking the excitement of a live pop performance" (Goodwin, 1993: 18).

To interrogate this further, consider the different states of attention when watching a film, watching television and listening/watching at a gig or concert. In film, the embodied experience is meant to be suppressed: you sit in a darkened space and the social codes of talking or laughing beyond a direct reaction to the film is frowned upon. Television is watched more casually and can serve either as a direct point of engagement or an element can be discussed, "talked over" or ignored as desired. At a live concert or gig, audience members are on show. They can see each other and they can be seen by the musicians. Visible embodied responses are more acceptable, even expected: clapping, cheering, talking (or yelling, depending on the volume) about what is seen or heard, moving to the pulse or full-on dancing to the music. The normative spectatorship of music involves embodied response; in this, the embodied responses to the visual, aural, and kinaesthetic elements of music videos involve potential for a similarly active sensorial state of spectatorship. 


\section{Action and the Embodiment of Identity}

As one would imagine, the body has long been a central consideration by dance academics and, more recently, an established concern within the social sciences. Introducing a volume on The Sociology of the Body, Cregan explains that "the body until recently has been largely taken for granted [but] over the past two decades this has changed. The body and embodiment have become objects of direct critical reflection" (2006: 1). Sociologist John O'Neill states that "society is never a disembodied spectacle [as] we engage in social interaction from the very start on the basis of sensory and aesthetic expressions" (1985: 22, italics in original). Writings on embodiment and the sociology of the body have grown to identify how human action and meaning is constructed, deconstructed, subverted, parodied, etc. in a number of socially defined settings (Goffman 2005, Cregan 2006, Waskul et al 2006, Shilling 2007). In this, embodied actions implicit within social rituals and the 'staging' of these interactions are central to the "collaborative manufacture of selves" as understood in both individual and collective identities (Charon, 1998: 191). The growing literature around the sociology of the body has fed into subsequent writings on dance in relation to identity, society, 'world cultures' and popular culture (Thomas 1993, Dils et al 2001, Dyck et al 2003, Franko 2002, Grau 2008), addressing the gap highlighted via McRobbie earlier in this chapter. Albright (1997) emphasizes the extents to which "culture is embedded in experiences of the body and [the] body is implicated in our notions of identity" (5). In Polhemus's discussion of "physical culture" encompassing our "non-verbal communicative systems," he states:

While physical culture may be viewed as a crystallisation - an embodiment - of the most deeply rooted and fundamental level of what it means to be a member of a particular society, dance might be seen as a second stage of this process - a schema, an abstraction or stylising of physical culture" (1993: 7).

In an essay exploring 'movement as culture' across disco dance and contact improvisation, Cynthia Cohen Bull (2001) positions "structured movement systems like social dance, theatre dance, sport, and ritual" as fundamental tools that "help to articulate and create images of who people are and what their lives are like, encoding and eliciting ideas and values; they are also part of experience, of performances and actions by which people know themselves" (405). Bull's connection between "images of who people are" and "actions by which they know themselves" evoke both the static and active elements of identity, highlighting the role that the body (noun) moving (verb) plays in the ongoing construction of one's sense of self in relation to others.

The action of dancing is a conscious one. It involves the choice to move in ways that are kinaesthetically experienced and outwardly visible. The reasons one might choose to dance - leisure, 
ritual, enactment on cultural identity, self-expression, physical enjoyment, connection with others, display prowess in skills, to amuse - vary, but in the action of dancing, individuals draw on "human agency" which, as outlined by Noland (2009), is implicitly kinaesthetic and explicitly embodied:

...embodiment [is] the process whereby collective behaviors and beliefs, acquired through acculturation, are rendered individual and 'lived' at the level of the body. Agency, it follows, is the power to alter those acquired behaviors and beliefs for purposes that may be reactive (resistant) or collaborative (innovative) in kind" (9, italics in original).

When revisiting the act of dancing as conscious, kinaesthetically experienced, and outwardly visible, this concept of agency could not be more closely felt. But this power to both alter and activate one's kinaesthetic potential is not fixed. As one continually refines, expands, tests or neglects the practices s/he has learned, the embodied agency which facilitates the choice to act changes. And therein lies the importance of both the choice and risk involved in the embodied action of dancing. On one hand, contemporary physical culture offers such an array of embodied practices to participate in or adopt/adapt as an individual. Dodd highlights the need "to recognize that audiences have a powerful degree of agency in deciding whether to choose any of the commodities offered [in music videos], be it the music itself, the lifestyle of the artist, the dance style, or the body image on display" (2009: 259). But the choice to acquire new behaviours leads to a potential risk, as outlined by Shilling (2007) within his concept of "body pedagogics". In asserting that the "idea that social norms and social actions inhere within the deepest fibres of out bodily being", he emphasizes "the experiences that people go through when acquiring (or failing to acquire) new skills and capacities" (13). The visibility of dance and its implicit possibility of failure when working to acquire new capacities are palpably risky. And here again, the $21^{\text {st }}$ century music video offers an interesting subject in considering agency, identity and dance: widely accessible through the internet, potential to observe or re-enact content publically or privately, the music video offers not only music to be heard and images to be observed, but also a pedagogic tool that can directly influence one's behaviours, beliefs and the power to activate them as expression of identity.

\section{Dance as Embodied Identities of Music/Musician}

For decades preceding the advent of the music video, the role of popular music has been central in the processes of adolescence as "a struggle of emancipation from [one's] parents" during a transfer 
of "dependency to the peer group whose values are typically in conflict with those of [the] parents" (Bandura cited in Hudson, 1985: 35). Whiteley highlights the core role that identity plays in popular music, in relation to both the creator and the listener, stating:

It is arguably the case that live performance remains one of the principle constituents in notions of rock authenticity... In particular, the significance of live performance lies in its focus on identity, in its expression of emotions which, for examples, a listener may not be able to articulate because of personal repression or sexual taboos. This popular music locates the pleasures that are available, the sites where desire and power are invested and operationalised, and the possibilities for both determination and resistance. In turn, the power of music relies on an investment by a particular social or cultural group; its strength lies in its ability to create a feeling of belonging" (1997: xiv-xv).

Whiteley relates the key terms uses in this statement (authenticity, identity, repression, pleasure, desire, power, 'a feeling of belonging) to identity within live performance, but I would argue that it is not just the flesh-and-blood proximity which defines this live-ness. It is also the action fundamental to the embodiment of the song - the acts of singing, eye contact and gesture towards the crowd, the physicality of playing an instrument, facial expression - and the dual actions of witnessing and response which further distils this connection of identity between the musician and audience.

The star identities constructed in and through these performances play important roles as "they enable us to see that characterization, fiction, and perhaps event narrative itself exist in popular music at the point of narration... [The] creation of character identities for pop stars provides a point of identification for the listener-spectator" (Goodwin 1993: 103). This 'point of identification' is key, allowing sense of action, reaction, and interaction around the embodied identity of the star, the song, and the audience's individual and collective engagement with these identities: they are like me, I am like them, they are like us.

Simultaneously, another aspect is at play in these performances: the identity of the virtuoso. Judith Hamera draws together past descriptions of music and dance virtuosos - angels, devils, magicians, machines, geniuses, monsters - stating: "as these images suggest, virtuosos are human but not quite: they are something else, something more than the sum of their merely human parts" (2012: 753). But she goes on to describe virtuosity as a "relational economy", one that does more than relating the virtuoso to observing another by setting them apart from him or her. Instead she explores the connection made between the virtuoso and the audience in performance: they recognise the power and affect created while simultaneously seeing the common humanity of the individual embodying this virtuosity. "Virtuosos incarnate 'plots of possibility' for audiences - 
seemingly mastery of one's own labour and the affective surplus it generates - even while demonstrating the audience's inability to activate these plots themselves. They are objects of both attraction and anxiety" (Hamera, 2012: 753).

Virtuosity in musicianship is an obvious element within the pop star's identity, but for those stars for whom dance plays a strong (if not equal) role in their performances, the effect of virtuosic dancing can be transformative on perception of their identity. In her writings on Michael Jackson, Hamera (2012) explores "...a neglected aspect of virtuosity in dance more generally: its highly allegorical, nostalgic activation of imagined, idealized relationships between the body and work" (752). This aspect of virtuosity in dance pervades a number of dance forms; Hamera cites ballet as the pinnacle example citing ballet soloists who "beckon spectators with the phantasmic possibility of artisanal ownership of one's own labour through efforts so exceptional and so sublime they transcend even gravity" (2012, 752). Stars like Jackson, alongside Madonna, and more recently Pink and Florence Welch, demonstrate both the desire and realised potential to achieve a deeper physical and creative agency that goes beyond the charisma or presence valued in live music performance. It recognizes the risk involved in embodying such outwardly visible physical design and, when done with ease or success, can deepen the otherworldliness that Hamera speaks of as objects of "attraction and anxiety".

\section{Transferable Identities through Dance: from solo to ensemble}

The image of a pop star dancing within his or her video is familiar and, as discussed previously, elevates the perception of the star persona as virtuosic and agentic in embodying a range of ideal identities: physically fit, attractive to others, etc. But one must immediately note: they rarely dance alone. The pop star dancing as soloist is contextualized by the dancing and dancers that frame them, in relationship to their physical agency, social status and identity. The role that the dancing ensemble plays in music video varies, but one thing is constant. As they are observed dancing with or alongside the star figure, members of the ensemble share an embodied agency and kinaesthetic experience with him or her. They are connected through a shared action and, therefore, share an aspect in their individual embodied identities. As this occurs through dance and dance can be learned, this shared aspect is transferrable. "Music video is a platform both for the dilution and innovation of popular dance forms. Although, on the one hand, it operates through a form of cultural theft as it feeds off existing popular dance traditions as a means to promote its artists and attract 'commodity viewers,' it also serves as a pedagogical tool that circulates and distributes dance styles that audiences are keen to adopt and develop." (Dodds, 2009: 258-259). It is worth 
highlighting that the reality of learning dance sequences and styles has changed with the move of music video consumption from the television to the internet. "In domestic settings... young people can respond to recorded music and dance in the privacy of their own homes" (Dodds 2009: 247). And, without the curatorial power of music television stations to choose the timing and frequency of the play of music videos, they can be watched, re-watched, played in excerpt or slow-motion. Spectators can spend time in private, exploring and rehearsing embodied behaviours before or aside from experiences dancing with their peers, in a number of settings.

In placing the solo star amidst the ensemble, dance can communicate a series of messages regarding identity. However, three messages dominate as outlined (with somewhat simplified terminology) below:

- 'I am amazing': this approach highlights the ideal identities shared between the singer and ensemble, often displaying uniform, but consistently idealized bodies dancing in ideal ways. This approach accentuates the ability to transfer the agency acquired through dance whilst still reinforcing the 'star identity' as central.

- 'I am just like you': this emphasizes the collective identity but with the placement of the star identity as part of a group in a flat hierarchy

- 'You are as amazing as I am'; this approach also emphasizes the collective identity but by elevating status of the dancing 'everyman', accentuating and celebrating diversity in movement.

Numerous videos use one of these message in a singular, or at least dominant way. The first approach is perhaps the longest established and relies heavily on the presence and action of backing dancers. The identities of backing dancers have been treated in a number of ways. In some cases, backing dancers are stripped of their individual identity, by highly stylised hair and costume (as in Kylie Minogue's "Can't Get You Out of My Head" or Michael Jackson's "Thriller") or in showing their movement only in silhouette (as in "Strike it Up" by Black Box). In other cases, the backing dancers are wholly on view but styled to look like the star central to the video (as seen in Beyoncé's "Single Ladies"). Whether concealed or on show, the backing dancers represent an individual and collective idealized body, ideal both in physique and in the ability to perform movement "endlessly and with ease" (Aalten, 2007: 111). Backing dancers reinforce this idealized body as part of the star's identity, often grouped behind the singer, flanking or occasionally surrounding him or her. They serve to place dance at the forefront of the artist's viewable action, sometimes equal to the actual singing. Backing dancers are often used in more complex or difficult choreography and move in unison with 
the star. As a result, the collective effect of the movement is larger, often fills the majority of the screen space, and allows the 'amazing' singer to seemingly lead a chorus of skilled, moving, uniform bodies.

In the second approach, the movement is kept consciously simple and designed to be participatory (as in the Village People's "YMCA" or more recently, Psy's "Gangnam Style"). This power of dance is a tool for collective embodied identity. Tan (2015) explores the potential for this collection identity in his analysis of the Gangnam style global dance phenomenon:

For the non-Korean speaking listener, Psy's incomprehensible rap mutterings can be ignored when bodies, regardless of nationality, gender, class, age, and ethnicity, move and mingle to the rhythms of the music... The moving body, driven by the rhythm, becomes the site of the global intercultural performative. Partaking in this Gangnam community exemplifies a mode of consumption that awards importance through a sharing of physical-virtual space. As Bauman posits, such a sharing of physical space with other actors engaged in a similar task or activity grants importance or prominence to this action through an 'approval of numbers'” (88).

The prominence of this action serves not to elevate the status of the star persona, but emphasized the non-hierarchical status between him and the other participants in the dance. McRobbie describes the activation of collective identities in the construction of song and dance numbers in Fame through almost ritualistic qualities: "[they] are constructed so as to seem to bind people together, uniting young and old, teachers and taught, performers and audiences in an expression of celebration" (1984: 152). While this approach is focused on a much simpler set of choreographed movement, the effect is the same: it offers the listener/spectator a low-risk possibility to participate in a collective action and therefore the opportunity to enter a celebratory, collective identity first presented and aligned with the star's and song's embodied identity.

\section{Fluid Identities through Dance: mixing messages and making connections in embodied action}

In the case of some videos, the identities of the star persona as singer and dancer are presented on equal pegging and the three messages outlined previously ('I am amazing'; 'I am just like you'; 'You are as amazing as ( $\mathrm{am}^{\prime}$ ) are interwoven to cumulatively shape the relationship between the star and the other dances in the video, playing continuously with the hierarchies evoked. In considering the movement alone, a mix of simple and virtuosic movement is used to physically move the star's embodied identity from that of elevated to collective. But it is the relationship between these 
embodied actions and actors that communicate such a strong message. To explore this notion through closer analysis, I take two videos which place dance as the central action of the video: Michael Jackson's "Smooth Criminal" and Madonna's "Hung Up". Each analysis will explore the ways in which these messages are mixed, elevate the connective potential of the dance, and heighten the importance of dance within the embodied identity of both the song and the singer. The analysis purposefully focuses on the physical action portrayed onscreen rather than the choices regarding framing, lighting, direction or cuts between shots. By bringing attention specifically to the bodies and actions visible, the intent is to reframe one's analytic focus to these concepts of embodied action and identity as well.

\section{"Smooth Criminal" (1987)}

The first actions and images cement Jackson as the central and elevated figure in the video. We see his shadow - larger than life - before he appears in a darkened city backstreet. The door into the 'speakeasy' opens in silence and a blinding light pours out to illuminate Jackson's whole body. He enters into a completely still and silent club; every person, bodies tense, is transfixed on him and the music transitions from silence into music by the miraculous flip of a coin, which flies through the air across the entire room into a jukebox. Jackson's rhythmic pulse of the hips acts as a starter pistol to the song and the full ensemble immediately springs into action. His costume - white suit and fedora - catch the light in this darkened, subterranean room and he positively glows. The stage is set and, prior to the first note, Jackson's character (playing both himself and an imagined other) is wellestablished as other-worldly, capable of miraculous feats and holds the highest status in the room. He is 'amazing'. But actions that follow continually interrupt and reassert this dominance.

"Smooth Criminal" is marked throughout by a series of complicated dance sequences, but Jackson almost never dances alone. Instead, he dances side-by-side in tight unison movement with others (often men until final sequence). Fedoras are tipped forward to conceal all of the face but the mouth and one has to struggle to see Jackson singing. Besides the colour of his suit, there is no difference between the other men dancing. They look alike; they move alike. Jackson may be dominant but he is also like these men. A series of mime-like choreographies reasserts Jackson's dominance - violently dominant, sexually dominant- but also an ambiguous moral authority: he catches cheats at card games, at the pool table, men harassing a woman in a red dress. Each narrative interaction is stylised and dancerly in its movement, but the physical action that Jackson needs to assert to recapture the upper hand is minimal. The scale of his opponent's movement is almost twice that of Jackson, reinforcing not only his dominance but the sense of 'cool' alongside it. 
When Jackson does dance as a solo performer, he is a body moving in a sea of highly able bodies. The movement of the ensemble complements his solo action, relating him as a member of, but desirable within the group. In an early scene in the video Jackson dances with woman in red dress and five women mirror her movement in unison movement, positioned in a triangle behind her. Once can see that each 'desires' to be dancing with Jackson and, if not able to share proximity, can at least share in this corresponding movement. In a later scene, a solo occurs on the elevated gallery surrounding the main space and ensemble below responds physically in a call-and-response format before he descends slowly down the stairs to join the writhing crowd below. The choreography continually loops between messages of dominance and messages of belonging. The physical and creative agency of the group is palpably high and Jackson both is a fitting member and leader.

The narrative of the video includes other characters: three children who see Jackson in the street at the start of the film and watch the proceedings through a window. In a late part of the video, the third message is given: 'you are (or can be) as amazing as I am'. One of the little boy in the middle steps in the window and brags to his friends that he "taught him everything he knows" and immediately performs a choreographic phrase performed by Jackson and an all-male ensemble moments earlier. It is accurate, admirable, and fully convincing. The other two children shake their heads and turn their attention back to the window, but the scene is important in three ways. First, it positions outsiders-as-observers within the video. By casting these observers as children, the videomakers cleanse them of any association with the "sullied" aspects of the narrative: the violence, the sexually-charged encounters, and focuses their gaze on the dancing. Finally, it demonstrates the possibility for the outsiders/observers to re-enact, embody and therefore share this physical, danced identity. Jackson is there as a musician, obviously, but the boy does not grab a pretend microphone and sing; instead, he dances. Jackson's embodied identity is established, exalted and demonstrated as transferrable through dance, both by 'insiders' and 'outsiders' to the video's imagined community.

“Hung Up" (2005)

This video cuts between different sites where different people are executing a variety of dance- or movement-related actions and, through the video, people converge into one place and move together in collective dance-based or physical activity. A 'boom box'- distinct in shape and design - is a constant between the 'day' settings and while invisible in the 'night' setting, it is clear that the music in the club drives the bodies and the collective action. The video begins with Madonna entering an empty dance studio with the boom box, stripping down into a leotard and legwarmers and turning on the music (a tape, not a CD or mp3 player) before beginning to stretch and limber up. 
The video cuts to a group of young people - five men and one woman in t-shirts, loose jeans/trousers and trainers - on an urban rooftop under a dawn-like sky and shows the young woman also in a deep stretch. The scenes of physical preparation continue until the chorus hits and everyone springs into action. Madonna breaks into a series of chainé turns, three young people break into a run and leap between stairs and balconies. The preparation is done and it is time to practice.

A new scene is introduced: a street corner in a working class neighbourhood. A quick shot of a palm tree suggests Los Angeles. A group of four African American teenagers bust into movement as a fifth arrives with the boom box. But this is not a shared dance; each moves as a solo, with his/her own style and physical stylistic vernacular, and are pushed out of the way to make space for another solo. This is not a 'battle' as we might understand it within breakdancing; there will be no winner. But each of the young people want/need to make space to try their own movement, to find their own style. Simultaneously, the video cuts back to Madonna in the studio. At times, she sings, eyes fixed to the camera and only gently undulating to the music. In scenes when she is dancing, she is fixed on her own reflection but not in a long sequence of well-executed movement. She tries a few moves, steps away from the mirror, tries some different movements, and the sequences become longer between breaks as she seemingly finds movement that 'works'. Meanwhile four of the teenagers in the street scene grab the boom box, jump in an American yellow cab and leave the neighbourhood scene. Practice is over and it is time to dance.

These early scenes, making up a third of the video, disrupts the normative presentation of dance as virtuosity previously discussed. Dancers do not move "endlessly and with ease" (Aalten, 2007: 111) but instead must warm up and practice, must try and fail. The work that Hamera highlights within virtuosity is put on show; although the settings and the people are different, this sets a flat hierarchy between our disparate characters. Watching Madonna move, the listener/spectator carries the knowledge of her past prowess as a dancer, her decades of experience. But the common ground is made explicit prior to any full-out 'dancing'.

A new scene is introduced: a Chinese takeaway/restaurant at closing time. Two cooks leap over the counter into a series of inverted breakdancing acrobatics, and after a few moments, the first unison movements ensue. Meanwhile, in the dance studio, Madonna has found her groove and performs a longer sequence, aligning with the chorus of the song. But back to the restaurant where our ensemble of two grows to four and their unison movement is common with the dance phrase

\footnotetext{
2 The term 'full-out' is used in dance to denote dance activity that uses the maximum movement range, energy and performance quality possible in its execution. It stands aside from other activity in dance, such as the term 'marking' which refers to dance in a smaller scale which may be more focused on experimentation, building muscle memory for movement order or conserving energy in a rehearsal setting.
} 
performed by Madonna. In both settings, the mood is light, playful and celebratory. Work is over and it is time to dance.

The video transitions from day to night and the L.A. youths' American taxi becomes a London black cab. They tumble out, boom box on one man's shoulder, into a back street and depart. Madonna, now in jeans and a black leather jacket, on a similar street walking towards and with the camera. Occasionally, her gaze is drawn away by passing young men, but she continues walking with purpose. The characters converge in a club. It is dark, shadowy and the music, lights and bodies pump to the same heavy pulse. In slow-motion, away from the dance floor, Madonna moves with a small group of men and women introduced earlier in the video. The interaction starts as one man unzips her jacket, she brushes faces with another, her hips drop as the hips of another rise to meet hers. She pivots around a man with a leg outstretched as he descends towards her pelvis, their gazes fixed. She slides down one woman and undulates with another as the dance floor explodes into a slow-motion frenzy of unabashed, solo dances by all players. This scene continues, cut with images of Madonna (back in her leotard) continually moving over the boom box in the flashing lights of the club: a long chain of pelvic thrusts that lead to the climax of the ensemble dancing. Back in real time, the group moves together to the pulse of the music in and around a dance video game machine. It is a mix of virtuosity and community; many solo, many move in unison together in the phrase introduced earlier, many clap/smile/move in response. The groupdiverse in age, nationality, style - is one: through the music and through their dance.

The second phases of the video work explicitly to exalt two messages: 'I am like you' and 'you are as amazing as I am'. The diversity of individuals' movement isn't only incorporated alongside Madonna's dancing; it is central and exalted. Considering this diversity, Dodds writes, “Madonna [borrows] from other cultural communities, as in her video 'Hung Up' (2005), in which she incorporates krumping, a bewilderingly fast style of L.A. hip-hop dance. This use of cutting-edge social dance styles is clearly a means to position herself as an innovator close to underground street culture, yet this neatly sidesteps the issue of cultural appropriation" (2009: 256). But this analysis seeks to introduce another perspective. In this layering of preparation, practice, individual dance and collective dance, everyone's movement is aligned to their identities as presented and demonstrated: nationality, ethnicity, age, specialist skill base. Madonna's 'work' in the studio uses vernacular from jazz dance with splashes of ballet and disco. What is clear in the video's narrative is her desire to move with and like others, to grow her physical agency into new behaviours with new people and, through dance, share with a diverse but equal collective. This desire is strong and unrepentantly embodied, as images of moving with others shift between abstracted, but potent sexual intimacy, trance-like abandon on a darkened dance floor, and skilled dance sequences on the 
video game. Madonna's choreography does not copy the movement with others, but it embraces it and responds to it. Much could be written about the power and hierarchy implicit in a white, wealthy, mature female rock star moving within a group of people of vastly different ethnicity, age, and socio-economic standing; her status is reinforced in so many ways. But this video presents a narrative that places dance as the primary embodied identity and suspends all other aspects as secondary. It asserts, despite this diversity, the transferability of dance within danced identities and the common ground created when this shared exchange occurs. Like dance in so many music videos, "Hung Up" employs dance to formulate the embodied identity of the song, and through the song, the artist. As a kinaesthetic, action-based instrument, it taps into the identities of the artistboth fixed and fluid- and reinforces these identities something that can be observed, experienced, consumed, extended, or transferred.

In both videos, the stars in their roles as singers and dancer continually renegotiate their embodied identities between ones of elevation to ones positioned within a collective. The reactions to and participation with the songs by all actors in the videos are so deeply embodied, laying groundwork for similar participation by the videos' spectators as well. By considering dance as action-based rather than simply a visual component, one can see the potential for the design and integration of dance into these music videos provide a potent tool for connection between the song, the artist featured, and his/her audience.

\section{Bibliography}

Aalten, A. (2007) 'Listening to the Dancer's Body' in Shilling, C. (ed) Embodying Sociology: retrospect, progress and prospects, pages 109-125, Oxford: Blackwell Publishing. 
Albright, A.C. (1997) Choreographing Difference: the body and identity in contemporary dance, London: University Press of New England.

Bull, C.J.C. (2001) 'Looking at Movement as Culture: contact improvisation to disco' in Dils, A. and Albright, A.C. (eds) Moving History/Dancing Cultures: a dance history reader, Middleton: Wesleyan University Press.

Charon, J. M. (1998) Symbolic Interactionism: an introduction, an interpretation, an integration, $6^{\text {th }}$ ed., New Jersey: Prentice-Hall Inc.

Cregan, K. (2006) The Sociology of the Body, London: Sage Publications.

Dils, A. and Albright, A.C. (2001) Moving History/Dancing Cultures: a dance history reader, Middleton: Wesleyan University Press.

Dodds, Sheril (2009) 'From Busby Berkeley to Madonna: music video and popular dance', in J. Malnig (ed.) Ballroom, Boogie, Shimmy Sham, Shake: a social and popular dance reader, Chicago: University of Illinois Press.

Dyck, N. and Archetti, E.P (2003), Sport, Dance and Embodied Identities, New York: Berg.

Franko, M. (2002) The Work of Dance: labour, movement and identity in the 1930s, Middleton: Wesleyan University Press.

Goffman, E. (2005) Interaction ritual: essays on face-to-face behaviour, New Brunswick: Aldine Transaction.

Goodwin, A. (1993) Dancing in the Distraction Factory: music television and popular culture, London: Routledge.

Grau, A. (2008) 'Dance, Identity, and Identification Processes in the Postcolonial World' in Franko, S. and Nordera, M. (eds), Dance Discourses: keywords in dance research, p. 404-413, London: Routledge.

Hudson, B. (1985) 'Femininity and Adolescence' in McRobbie, A. and Nava, M. (eds), Gender and Generation, 31-53, London: Macmillan Education Ltd. 
McDonald, P. (1997) 'Feeling and Fun: romance, dance and the performing male body in Take That videos', in Whiteley, S. (ed), Sexing the Groove: popular music and gender, p. 259-276, London: Routledge.

McRobbie, A. (1984), 'Dance and Social Fantasy', in McRobbie, A. and Nava, M. (eds), Gender and Generation, 130-161, London: Macmillan Education Ltd.

Mercer, K. (1998) 'Monster Metaphors: notes on Michael Jackson's Thriller' in Frith, S., Goodwin, A. and Grossberd, L. (eds), Sound and Vision: the music video reader, $2^{\text {nd }}$ ed., p. 93-108, London: Routledge.

Shilling, C. (2007) Embodying Sociology: retrospect, progress and prospects, Oxford: Blackwell Publishing.

Straw, W. (1998), 'Pop Music and Postmodernism in the 1980s' in Frith, S., Goodwin, A. and Grossberd, L. (eds), Sound and Vision: the music video reader, $2^{\text {nd }}$ ed., p. 3-21, London: Routledge. Tan, M. (2015) K-Contagion: sound, speed and space in 'Gangnam Style', The Drama Review, 59(1), p. 83-96.

Thoman, H. (1993) Dance, Gender and Culture, London: Macmillan Press.

Waskul, D. \& Vannini, P. (2006) Body/Embodiment, Padstow: Ashgate Publishing House.

Whiteley, S. (1997) Sexing the Groove: popular music and gender, London: Routledge.

Whiteley, S. (1997), 'Seduced by the Sign: analysis of the textual links between sound and image in pop videos', in Whiteley, S. (ed), Sexing the Groove: popular music and gender, p. 277-294, London: Routledge. 